\title{
USING CORONARY SINUS DIAMETER AND COLLAPSE INDEX TO ESTIMATE RIGHT ATRIAL PRESSURE FOR ECHOCARDIOGRAPHIC SYSTOLIC PULMONARY ARTERIAL PRESSURE MEASUREMENT
}

GÜNDÜZALP SAYDAM ${ }^{1}$, Ali Kilinc ${ }^{2}$, Veysel Tosun ${ }^{3}$, Necmettin Korucuk ${ }^{1}$, Unal Guntekin $^{4}$, and mehmet yaman ${ }^{5}$

${ }^{1}$ Affiliation not available

${ }^{2}$ Arnavutköy State Hospital

${ }^{3}$ Sanliurfa Egitim ve Arastirma Hastanesi

${ }^{4}$ Akdeniz Universitesi Tip Fakultesi

${ }^{5}$ Ordu Universitesi

September 25, 2021

\begin{abstract}
Objective: According to Bernoulli Equation, systolic pulmonary artery pressure is obtained echocardiographically by adding estimated right atrial pressure (RAP) to the multiply of square of tricuspid regurgitation flow rate by four. RAP is estimated based on inferior vena cava (IVC) diameter and collapse. Our objective is to investigate usability of coronary sinus(CS) diameter and collapse, measured by echocardiography for estimating RAP. Methods: Our study is a single center, prospective study. 136 patients, over 18 years of age and without exclusion criteria, who admitted to Akdeniz University Hospital Cardiology Department between March 2017 and March 2018 and were scheduled to undergo right heart catheterization for any reason were included study. Results: Patients were divided into two groups as invasively measured RAP [?]10 mmHg (n: 57) and RAP $<10 \mathrm{mmHg}$ (n: 79). In group with RAP [?]10 mmHg, maximum IVC and CS diameter were higher than group with RAP $<10$ $\mathrm{mmHg}$, IVC and CS collapse indices were lower $(\mathrm{p}<0.001)$. Optimal cut-off value for maximum IVC diameter was $19.6 \mathrm{~mm}$ (sensitivity $63.2 \%$, specificity $87.3 \%$ ), for IVC collapse index was 46.1 (sensitivity $75 \%$, specificity $79.7 \%$ ), for maximum CS diameter was $11 \mathrm{~mm}$ (sensitivity $64.9 \%$, specificity $77 \%$ ), for CS collapse index was 39.2 (sensitivity $75.4 \%$, specificity $88.6 \%$ ). Conclusion: Significant relationship was found between invasively measured RAP and maximum IVC diameter, collapse index and maximum CS diameter and collapse index. Results of CS parameters were as significant as results of IVC parameters therefore it shows that CS can also be used for estimating RAP.
\end{abstract}

USING CORONARY SINUS DIAMETER AND COLLAPSE INDEX TO ESTIMATE RIGHT ATRIAL

PRESSURE FOR ECHOCARDIOGRAPHIC SYSTOLIC PULMONARY ARTERIAL PRESSURE

MEASUREMENT

Gündüzalp Saydam ${ }^{1}$, Ali Yaşar Kılınç ${ }^{2}$, Veysel Tosun ${ }^{3}$, Necmettin Korucuk ${ }^{4}$, Ünal Güntekin ${ }^{5}$, Mehmet Yaman $^{6}$

${ }^{1}$ Cihanbeyli State Hospital, Cardiology Department, Konya, Turkey 
${ }^{2}$ Arnavutköy State Hospital, Cardiology Department, Istanbul, Turkey

${ }^{3}$ Şanlıurfa Training and Research Hospital, Cardiology Department, Şanlıurfa, Turkey

${ }^{4}$ Antalya Memorial Hospital, Cardiology Department, Antalya, Turkey

${ }^{5}$ Akdeniz University Medical Faculty Hospital, Cardiology Department, Antalya, Turkey

${ }^{6}$ Ereğli Echomar Hospital, Cardiology Department, Zonguldak, Turkey

Corresponding Author: Gündüzalp Saydam, Cihanbeyli State Hospital, Cardiology Department

Address: Atçeken Neighborhood, Hastane Street, 42850 Cihanbeyli / Konya

Mail: gunduzalpsaydam@gmail.com

Tel No: 05367434182

Fax No: 03326734095

The authors have no conflict of interest declare.

No financial support was received for the study.

\section{Introduction}

Pulmonary hypertension (PHT) is a disease characterized by complex proliferation and progressive pulmonary vascular remodeling in the pulmonary vascular endothelium (1). With use of transthoracic echocardiography(TTE), it has become possible to estimate pulmonary artery pressure(PAP) by a noninvasive method. According to Bernoulli Equation, systolic PAP is obtained by adding estimated right atrial pressure (RAP) to the multiply of square of tricuspid regurgitation(TR) flow rate by four (2). When the estimated RAP is added to the transtricuspid gradient, calculated using the maximum jet of $\mathrm{TR}$, the calculated values are very close to the values of right ventricular(RV) systolic pressure measured by right heart catheterization(RHC) (3). Estimated RAP is determined by TTE based on inferior vena cava (IVC) diameter and collapse.

Normal value of RAP is $1-7 \mathrm{mmHg}(4)$. RAP is most commonly estimated according to IVC diameter and inspiratory collapse (5). As RAP increases, this increase is transmitted to IVC, resulting in IVC dilatation and reduction of inspiratory collapse. With the combination of these two parameters, we can predict RAP in most patients.

Both IVC and coronary sinus(CS) open directly into the right atrium(RA). CS is a tubular structure that draws a route in the atrioventricular groove located at the posterior of the heart and where large cardiac veins are poured. The diameter of the ostium varies between 4-5 $\mathrm{mm}$ and 9-15 $\mathrm{mm}(6)$. Echocardiographically, CS is best evaluated in apical four-chamber imaging (7).

There are some studies evaluating the relationship of RAP, estimated by non-invasive methods and systolic PAP with CS $(8,9)$. However, there is no study comparing invasively measured RAP with CS diameter and collapse and evaluating the utility of CS in noninvasive RAP estimation. The aim of our study is to evaluate the utility of CS diameter and collapse, which is a noninvasive method, for estimating RAP. In this way, new echocardiographic parameters will be defined for estimating RAP and PAP value will be determined more accurately and easily.

\section{Methods}

136 patients over the age of 18, who admitted to Akdeniz University Hospital Cardiology Department between March 2017 and March 2018 and were scheduled to undergo right heart catheterization(RHC) for any reason were included the study. Patients with congenital heart disease, who had undergone surgery due to congenital heart disease in childhood, whose echocardiographic evaluations could not be made due to poor echogenicity and patients with missing RHC data were excluded from the study. 
Each individual included in the study was informed about the study and a written consent form was read and signed. The study protocol was approved by the local ethics committee and was performed in accordance with the Declaration of Helsinki.

RAP, RV end-diastolic pressure, RV systolic pressure, PA pressures (systolic, mean, diastolic) and pulmonary capillary wedge pressure (PCWP) were measured by RHC. Measurements were evaluated at the end of expiration.

Echocardiographic examinations of the patients were performed by an experienced specialist at the Echocardiography Laboratory of the Akdeniz University Cardiology Department. The patients were placed in the left lateral decubitus position. Echocardiographic evaluations were performed in the presence of electrocardiographic rhythm monitoring. Standard two-dimensional echocardiography, M-mode echocardiography and doppler examinations were performed through apical, parasternal and subcostal windows in accordance with the recommendations of the American Echocardiography Society. Parameters were taken in accordance with these guideline recommendations and relevant measurements were calculated according to these guideline recommendations (10). The CS diameter was visualized in the posterior region between LA and LV, with a slight posterior tilting of the probe at the level of the mitral annulus in apical 4-chamber window. Maximum and minimum diameter of CS was measured by M-Mode echocardiography method (Figure-1). CS collapse index (CSCI) was calculated by the following formula:

$=\%[($ CSDmax - CSDmin $)] /$ CSDmax x 100 CSDmax: Maximum CS diameter, CSDmin: minimum CS diameter

IVC measurements were made through a standard subcostal echocardiographic window. The intrahepatic region where IVC joins to the RA was visualized. After expiration, IVC' $\mathrm{s}$ maximum diameter, minimum diameter and respiratory change were measured $1-2 \mathrm{~cm}$ near the point where the IVC joins the RA. IVC collapse index (IVCCI) was calculated by the following formula:

$=\%[($ IVCDmax - IVCDmin $)] /$ IVCDmax x 100

IVCDmax: Maximum IVC diameter, IVCDmin: minimum IVC diameter

Body surface areas (BSA) of the patients were calculated and CS and IVC parameters were also analyzed by indexing with BSA.

Descriptive statistics are presented with mean, percentage and standard deviation values. Fisher's Exact Test or Pearson's chi-square test was used in the analysis of the relationships between categorical variables. In the analysis of the difference between the measurement values of the two groups, Mann-Whitney $U$ test was used when the distribution of the data did not comply with the normal distribution and Student's t test was used if it did. Spearman correlation test was used for continuous variables not conforming to ordered or normal distribution and Pearson correlation test was used for continuous variables that conforming to normal distribution. $\mathrm{p}$ values less than 0.05 were considered statistically significant. In order to estimate the increase in RAP measured by catheterization, "Receiver-Operating Characteristic (ROC)" curves were created for each IVC and CS parameter and optimal cut-off values were determined from them. In addition, sensitivity, specificity, positive and negative predictive values were found for the increased RAP value. Study data were analyzed in "MedCalc" and "SPSS 25.0 for Windows" programs.

\section{Results}

136 patients, whose TTE and RHC data were analyzed were included in the study. The mean age of the patients included in the study was $57.67 \pm 13.36$ and 59 (43.4\%) patients were male. General characteristics, clinical features, TTE and RHC findings of the patients are shown in Table-1. IVCDmax, IVCDmin and IVCCI values were $18.5 \mathrm{~mm}, 11.14 \mathrm{~mm}, 42.41 \%$, respectively. CSDmax, CSDmin and CSCI values were $11.46 \mathrm{~mm}, 6.92 \mathrm{~mm}, 40.58 \%$, respectively.

The average RAP was measured as $9.84 \pm 5.39 \mathrm{mmHg}$. In 57 patients, invasively measured RAP was [?]10 $\mathrm{mmHg}$, in 79 patients RAP was $<10 \mathrm{mmHg}$. In the group with RAP [?]10 $\mathrm{mmHg}$, the diameters of IVC 
and CS and their diameters indexed to BSA were higher than the group with RAP $<10 \mathrm{mmHg}$. In addition, in the group with RAP[?]10 mmHg, IVCCI and CSCI and collapse indices indexed to BSA were lower. All parameters were statistically significant $(\mathrm{p}<0.001)($ Table-2).

CS and IVC parameters of the patients included in the study were compared with each other as well as with invasively measured RAP values and the correlation between them was evaluated. CSDmax and CSDmax/BSA were compared with IVCDmax and IVCDmax/BSA and a moderate relationship was found between them(r: $0.554 \mathrm{p}<0.001 ; \mathrm{r}: 0.597 \mathrm{p}<0.001$, respectively). CSDmin, CSDmin/BSA and CSCI were compared with IVCDmin, IVCDmin/BSA and IVCCI and a high level of significant relationship was found between them(r: $0.712 \mathrm{p}<0.001 ; \mathrm{r}: 0.717 \mathrm{p}<0.001 ; \mathrm{r}$ : $0.608 \mathrm{p}<0.001$ respetively)(Figure-2).

Invasively measured RAP was compared with CSDmax and CSDmax/BSA and a moderate significant correlation was found between them (r: $0.478 \mathrm{p}<0.001 ; \mathrm{r}: 0.484 \mathrm{p}<0.001$, respectively). Invasively measured RAP was compared with CSDmin, CSDmin/BSA and CSCI and a high level of significant relationship was found between them(r: $0.711 \mathrm{p}<0.001 ; \mathrm{r}: 0.691 \mathrm{p}<0.001 ; \mathrm{r}:-0.674 \mathrm{p}<0.001$, respectively)(Figure-3).

There was a moderately significant relationship between RAP and IVCDmax and IVCDmax/BSA(r: $0.615 \mathrm{p}<0.001, \mathrm{r}: 0.518 \mathrm{p}<0.001)$. Finally, there was a high level of significant correlation between RAP and IVCDmin, IVCDmin/BSA and IVCCI ( $\mathrm{r}: 0.705 \mathrm{p}<0.001 ; \mathrm{r}: 0.659 \mathrm{p},<0.001 ; \mathrm{r}:-0.683 \mathrm{p}$ $<0.001$ respectively)(Figure-4).

According to ROC analysis; for predicting RAP[?]10 mmHg, optimal cut-off value of IVCDmax was found to be $19.6 \mathrm{~mm}$ (sensitivity, $63.2 \%$; specificity, $87.3 \%$ ), optimal cut-off value of IVCDmax/BSA was found to be $10,6 \mathrm{~mm} / \mathrm{m} 2$ (sensitivity, \%64,9; specificity,\%81), optimal cut-off value of IVCDmin was found to be $10 \mathrm{~mm}$ (sensitivity, \%73,7; specificity,\%82,3), optimal cut-off value of IVCDmin/BSA was found to be $5,8 \mathrm{~mm} / \mathrm{m} 2$ (sensitivity, \%68,4; specificity, \%87,3), optimal cut-off value of IVCCI was found to be 46,1 (sensitivity, \%75,4; specificity, \%79,7), optimal cut-off value of CSDmax was found to be $11 \mathrm{~mm}$ (sensitivity, $\% 64,9$; specificity, \%77,3), optimal cut-off value of CSDmax/BSA was found to be $5,8 \mathrm{~mm} / \mathrm{m} 2$ (sensitivity, $\% 77,1$; specificity,\%58,2), optimal cut-off value of CSDmin was found to be $6,1 \mathrm{~mm}$ (sensitivity, \%84,2; specificity, \%77,2), optimal cut-off value of CSDmin/BSA was found to be $3,6 \mathrm{~mm} / \mathrm{m} 2$ (sensitivity, \%78,9; specificity,\%79,7), optimal cut-off value of CSCI was found to be 39,2 (sensitivity, \%75,4; specificity, \%88,6). All parameters were statistically significant $(\mathrm{p}<0.001)$ (Table-3).

\section{Discussion}

In our study, we evaluated the relationship between RA pressure, measured by RHC and IVC, CS diameters and their collapse. It is known that IVC diameter and collapse are used to predict RA pressure(11). However, there is no data on the use of CS diameter and collapse to predict RA pressure. There are a number of studies evaluating CS diameter and collapse in PHT, but there is no study evaluating the relationship between invasively measured RAP and CS.

In our study, the patients were divided into two groups as the group with invasively measured RAP values of $10 \mathrm{mmHg}$ and / or above and below $10 \mathrm{mmHg}$. The group with RAP[?]10 $\mathrm{mmHg}$ consisted of 57 individuals and the group with RAP $<10 \mathrm{mmHg}$ comprised 79 individuals. It was observed that the CSDmax and CSDmin were higher and CSCI was lower in the group with RAP [?]10 mmHg. This difference has reached statistical significance $(\mathrm{p}<0.001)$. In addition, we noticed that the results did not change when we indexed CS parameters to BSA. In addition, correlations of invasive RAP and CS parameters were evaluated and a significant correlation was found between them.

We examined the relationship between IVC diameter, collapse index and RAP and it was seen that IVC diameters were higher and IVC collapse indices were low in the group with RAP [?]10 $\mathrm{mmHg}(\mathrm{p}<0.001)$. Again, the analysis of the data obtained by indexing these parameters to BSA did not change the results. In previous studies comparing invasive RAP and IVC parameters, a moderate correlation was found between the two parameters (r: 0.35-0.76) (10,12). Similar to previous studies, in our study, a significant correlation was found between IVCDmax, IVCDmin and IVCCI parameters and invasive RAP. 
In our study, unlike the studies in the literature, the correlations of IVC and CS parameters with each other were evaluated. It was observed that there was a significant correlation in all IVC and CS parameters (maximum and minimum diameter, collapse index). The correlation coefficient for the maximum IVC and CS diameter was 0.554, and the correlation coefficient for the IVC and CS collapse index was 0.608.

In our study, we determined cut-off values predicting RAP to be $10 \mathrm{~mm} \mathrm{Hg}$ and above using ROC analysis for both IVC and CS. The cut-off values stated in the guidelines and used in estimating RAP are 21 $\mathrm{mm}$ for IVC diameter and $50 \%$ for IVCCI $(10,11)$. In a study by Kawata et al. In 2017, invasive RAP and echocardiographic IVC parameters were analyzed in 120 patients. The cut-off values, sensitivity and specificity of IVC parameters predicting RAP $>10 \mathrm{mmHg}$ were determined. The cut-off value for IVCDmax was found to be $17 \mathrm{~mm}$, and the cut-off value for IVCCI was found to be $40 \%$ (13). When we invastigated the correlation of invasive RAP with IVCDmax and IVCCI, the correlation coefficients in our study were higher. We found the cut-off values for IVCDmax and IVCCI lower than the values in the guidelines (19.6 $\mathrm{mm}, 46.1 \%$ respectively). The cut-off values we obtained for the CSDmax and CSCI were $11 \mathrm{~mm}$ and $39.2 \%$ respectively. In previous studies, no cut-off value was specified for CS to predict RAP[?]10 mmHg. Our study is the first study on this subject.

In a study in the literature, 155 patients included in the study were divided into 3 groups as patients with no PHT, moderate PHT and severe PHT. It was observed that as the systolic PAP value increased, CS dilation increased $(\mathrm{p}<0.001)$ and a significant correlation was found between CS and IVC ( $\mathrm{r}: 0.416 ; \mathrm{p}<0.001)(14)$. The results in our study were similar and the correlation coefficient between IVC and CS was found to be higher $(\mathrm{r}: 0,554, \mathrm{p}<0,001)$.

In our study, the correlation between invasively measured RAP and estimated RAP calculated by IVC was also examined and found to be highly significant $(\mathrm{r}: 0.765, \mathrm{p}<0.001)$. This high correlation of the estimated RAP with the invasively measured RAP reveals the reliability of the echocardiography examination we have made.

In a study conducted with 215 people, the systolic PAPs of the patients were calculated according to the Bernoulli equation with echocardiography. The patients were divided into two groups as those with systolic PAP above $35 \mathrm{mmHg}$ (n: 109) and those without. CS diameters were higher in the PHT group ( $<0.001)$. At the same time, the estimated RAP values were calculated according to the IVC diameter and collapse of the patients. The correlation of RAP, calculated by IVC, with the maximum diameter of the CS was examined and found to be statistically significant $(\mathrm{r}=0.557, \mathrm{P}<0.001)(9)$. In our study, pressures were measured invasively and it was observed that the diameter of the CS was more dilated in patients with high invasive pressures. It was observed that both the estimated RAP calculated by IVC and the invasively measured RAP were correlated with the CS parameters. In addition, differently, maximum diameters, minimum diameters, CS collapse index and their ratio to BSA were evaluated and all of them were found to be statistically significant.

In a study of 43 people conducted by Mahmud et al. in 2001, RA pressures were measured invasively and compared with the minimum CS diameter measured from the parasternal long axis and significant results were obtained ( $\mathrm{r}: 0.59, \mathrm{P}<0.001)(15)$. In our study, IVCDmin was found to be higher in the group with high invasive RAP. In addition, in our study, ROC analyzes were performed for CSDmax, CSDmin, CSDmax/BSA, CSDmin/BSA and CSCI in order to predict RAP [?]10 mmHg and their sensitivity and specificity were calculated and optimal cut-off values were determined. All CS parameters including CSDmin have been shown to be useful for RAP estimation.

\section{Limitation of Study}

Our study is a single center study. Most of the patients included in the study were people with cardiac disease, so no comparison could be made with healthy individuals. RHC and TTE were not performed simultaneously. There was a period of up to 48 hours between the two. Finally, the study population was relatively small. Multicenter studies with higher populations are needed on this subject. 


\section{Conclusion}

Our study is the first catheterization-supported study on the use of CS diameters and collapse in RAP estimation. IVC and CS parameters were evaluated with invasively measured RAP and significant results were obtained. That CS parameters are as significant as IVC parameters, shows that CS can now be used in RAP estimation. The high level of significance of correlation analyzes further strengthens this idea. Cut-off values for CS parameters have been determined in our study and will be an example for future studies.

\section{References}

1. Guignabert C., Girerd B., Ricard N., Huertas A., Montani D., Humbert M. New Molecular Targets of Pulmonary Vascular Remodeling in Pulmonary Arterial Hypertension. CHEST2015; 147 ( 2 ): 529 537.

2. Currie P.J., Seward J.B., Chan K.L. Continuous wave Doppler determination of right ventricular pressure: a simultaneous Doppler-catheterization study in 127 patients. J. Am. Coll. Cardiol. 1985;6(4):750-756.

3. Yock PG, Popp RL. Noninvasive estimation of right ventricular systolic pressure by Doppler ultrasound in patients with tricuspid regurgitation. Circulation 1984; 70: 657-62.

4. Kircher BJ, Himelman RB, Schiller NB. Noninvasive estimation of right atrial pressure from the inspiratory collapse of the inferior vena cava. Am J Cardiol 1990; 66: 493-6.

5. Moreno FL, Hagan AD, Holmen JR, Pryor TA, Strickland RD, Castle CH. Evaluation of size and dynamics of the inferior vena cava as an index of right-sided cardiac function. Am J Cardiol 1984; 53: 579-85.

6. Ortale JR, Gabriel EA, Iost C, Marquez CQ. The anatomy of the coronary sinus and its tributaries. Surg Radiol Anat 2001; 23: 15-21.

7. Andrade JL, Somerville J, Carvalho AC, Campos O Jr, Mitre N, Martinez EE, et al. Echocardiographic routine analysis of the coronary sinus by an apical view: Normal and abnormal features. Texas Heart Institute J 1986; 13(2): 197-202.

8. Cetin M., Cakici M., Zencir C., Tasolar H., Cil E., Yıldız E. et al. Relationship between severity of pulmonary hypertension and coronary sinus diameter. 2014 Sociedade Portuguesa de Cardiologia 10.1016/j.repce.2015.05.011.

9. Gunes Y, Guntekin U, Tuncer M, Kaya Y, Akyol A. Association of Coronary Sinus Diameter with Pulmonary Hypertension. Echocardiography 2008; 25(9): 935-40. doi: 10.1111/j.1540-8175.2008.00718.x

10. Lang RM, Badano LP, Mor-Avi V, Afilalo J, Armstrong A, Ernande L, et al. Recommendations for cardiac chamber quantification by echocardiography in adults: An update from the American Society of Echocardiography and the European Association of Cardiovascular Imaging. J Am Soc Echocardiogr 2015; 28: $1-39$.

11. Rudski LG, Lai WW, Afilalo J, Hua L, Handschumacher MD, Chandrasekaran K, et al. Guidelines for the echocardiographic assessment of the right heart in adults: a report from the American Society of Echocardiography endorsed by the European Association of Echocardiography, a registered branch of the European Society of Cardiology, and the Canadian Society of Echocardiography. Journal of the American Society of Echocardiography: official publication of the American Society of Echocardiography 2010; $23(7)$ : 685-713; quiz 786-688.

12. Otto CM. Textbook of Clinical Echocardiography. Philadelphia: Elsevier Saunders, Inc, 2004, 131-65.

13. Kawata T, Daimon M, Lee SL, Mimura K, Sawada N, Chiang SJ, et al. Reconsideration of Inferior Vena Cava Parameters for Estimating Right Atrial Pressure in an East Asian Population, Comparative Simultaneous Ultrasound- Catheterization Study. Circulation Journal 2017; 81(3): 346-52.

14. Cetin M, Cakıcı M, Zencir C, Tasolar H, Cil E, Yildiz E, et al. Relationship between severity of pulmonary hypertension and coronary sinus diameter. Rev Port Cardiol 205; 34(5): 329-35.

15. Mahmud E, Raisinghani A, Keramati S, Auger W, Blanchard DG, DeMaria AN. Dilation of the Coronary Sinus on Echocardiogram: Prevalence and Significance in Patients with Chronic Pulmonary Hypertension. J Am Soc Echocardiogr 2001; 14(1): 44-9. 
Tables and Figures

\begin{tabular}{|c|c|}
\hline Variable & n:136 \\
\hline Age (years) & $57,67 \pm 13,36$ \\
\hline Male (\%) & $59(43,4)$ \\
\hline $\mathrm{BMI}\left(\mathrm{kg} / \mathrm{m}^{2}\right)$ & $27,81 \pm 5,27$ \\
\hline $\operatorname{BSA}\left(\mathbf{m}^{2}\right)$ & $1,83 \pm 0,19$ \\
\hline Systolic Blood Pressure (mmHg) & $125,92 \pm 20,56$ \\
\hline Diastolic Blood Pressure (mmHg) & $72,86 \pm 9,95$ \\
\hline \multicolumn{2}{|l|}{ Comorbidities } \\
\hline Diabetes Mellitus (\%) & $43(31,6)$ \\
\hline Hypertension (\%) & $68(50)$ \\
\hline Ischemic Heart Disease (\%) & $36(26,5)$ \\
\hline Atrial Fibrillation $(\%)$ & $50(36,8)$ \\
\hline Smoking (\%) & $33(24,3)$ \\
\hline Lung Disease (\%) & $16(11,8)$ \\
\hline \multicolumn{2}{|l|}{ Hemodynamic Data } \\
\hline PASP (mmHg) & $49,22 \pm 22,86$ \\
\hline PADP (mmHg) & $21,64 \pm 9,96$ \\
\hline PAMP (mmHg) & $32,9 \pm 13,49$ \\
\hline HR (beats/min) & $81,43 \pm 13,75$ \\
\hline $\mathrm{RAP}(\mathrm{mmHg})$ & $9,84 \pm 5,39$ \\
\hline RAP [?]10 mmHg (n(\%)) & $57(41,9)$ \\
\hline \multicolumn{2}{|l|}{ Ultrasound Data } \\
\hline IVCDmax (mm) & $18,5 \pm 4,94$ \\
\hline $\operatorname{IVCDmin~(mm)~}$ & $11,14 \pm 5,62$ \\
\hline $\operatorname{IVCDmax} / \mathrm{BSA}\left(\mathrm{mm} / \mathrm{m}^{2}\right)$ & $10,2 \pm 2,73$ \\
\hline IVCDmin/BSA $\left(\mathrm{mm} / \mathrm{m}^{2}\right)$ & $6,12 \pm 2,98$ \\
\hline IVCCI $(\%)$ & $42,41 \pm 13,95$ \\
\hline CSDmax (mm) & $11,46 \pm 2,48$ \\
\hline CSDmin $(\mathrm{mm})$ & $6,92 \pm 2,39$ \\
\hline CSDmax/BSA $\left(\mathrm{mm} / \mathrm{m}^{2}\right)$ & $6,32 \pm 1,4$ \\
\hline $\mathrm{CSDmin} / \mathrm{BSA}\left(\mathrm{mm} / \mathrm{m}^{2}\right)$ & $3,8 \pm 1,25$ \\
\hline CSCI $(\%)$ & $40,58 \pm 11,05$ \\
\hline
\end{tabular}

Table-1: General Characteristics, Hemodynamic and Ultrasound Data of the Study Patients

BMI donates body mass index, BSA:body surface area, CS:coronary sinus, CSD:coronary sinus diameter, CSCI:coronary sinus collapsibility index, HR:heart rate, IVC:inferior vena cava, IVCCI:inferior vena cava collapsibility index, IVCD:inferior vena cava diameter, PADP: pulmonary artery diastolic pressure, PAMP:pulmonary artery mean pressure, PASP:pulmonary artery systolic pressure, RAP:right atrial pressure.

Tablo-2: Comparison of IVC and CS parameters in the groups with RAP[?]10 mmHg and RAP $<10 \mathrm{mmHg}$

\begin{tabular}{llll}
\hline Variable & $\begin{array}{l}\text { RAP[?]10 } \mathbf{m m H g} \\
(\mathbf{n : 5 7 )}\end{array}$ & $\begin{array}{l}\mathbf{R A P}<\mathbf{1 0} \mathbf{m m H g} \\
(\mathbf{n : 7 9})\end{array}$ & $\mathbf{p}$ \\
\hline IVCDmax $(\mathbf{m m})$ & $21,61 \pm 5,45$ & $16,26 \pm 2,96$ & $\mathbf{p}<\mathbf{0 , 0 0 1}$ \\
IVCDmin $(\mathbf{m m})$ & $14,97 \pm 6,4$ & $8,37 \pm, 61$ & $\mathbf{p}<\mathbf{0 , 0 0 1}$ \\
IVCDmax $/ \mathbf{B S A}\left(\mathbf{m m} / \mathbf{m}^{\mathbf{2}}\right) 1,64 \pm 2,9$ & $9,16 \pm 2,06$ & $\mathbf{p}<\mathbf{0 , 0 0 1}$ \\
IVCDmin $/ \mathbf{B S A}\left(\mathbf{m m} / \mathbf{m}^{\mathbf{2}}\right) 8,04 \pm 3,3$ & $4,73 \pm 1,71$ & $\mathbf{p}<\mathbf{0 , 0 0 1}$
\end{tabular}




\begin{tabular}{llll}
\hline Variable & $\begin{array}{l}\text { RAP[?]10 } \mathbf{m m H g} \\
(\mathbf{n : 5 7 )}\end{array}$ & $\begin{array}{l}\mathbf{R A P}<\mathbf{1 0} \mathbf{m m H g} \\
(\mathbf{n : 7 9})\end{array}$ & $\mathbf{p}$ \\
\hline IVCCI$(\%)$ & $33,12 \pm 14,63$ & $49,11 \pm 8,64$ & $\mathbf{p}<\mathbf{0 , 0 0 1}$ \\
CSDmax $(\mathbf{m m})$ & $12,4 \pm 2,37$ & $10,78 \pm 2,34$ & $\mathbf{p}<\mathbf{0 , 0 0 1}$ \\
CSDmin(mm) & $8,54 \pm 2,42$ & $5,76 \pm 1,54$ & $\mathbf{p}<\mathbf{0 , 0 0 1}$ \\
CSDmax/BSA $\left(\mathbf{m m} / \mathbf{m}^{\mathbf{2}}\right)$ & $6,68 \pm 1,22$ & $6,06 \pm 1,48$ & $\mathbf{p}<\mathbf{0 , 0 0 1}$ \\
CSDmin/BSA $\left(\mathbf{m m} / \mathbf{m}^{\mathbf{2}}\right)$ & $4,59 \pm 1,22$ & $3,24 \pm 0,94$ & $\mathbf{p}<\mathbf{0 , 0 0 1}$ \\
CSCI(\%) & $31,85 \pm 9,9$ & $46,87 \pm 6,73$ & $\mathbf{p}<\mathbf{0 , 0 0 1}$ \\
\hline
\end{tabular}

BSA donates body surface area, CS:coronary sinus, CSD:coronary sinus diameter, CSCI:coronary sinus collapsibility index, IVC:inferior vena cava, IVCCI:inferior vena cava collapsibility index, IVCD:inferior vena cava diameter, RAP:right atrial pressure.

Table-3: Receiver-Operating Characteristic Curve analysis of IVC and CS parameters predicting RAP [?]10 $\mathrm{mmHg}$

\begin{tabular}{|c|c|c|c|c|c|c|c|}
\hline Varible & AUC & $P$ value & Cut-off & $\begin{array}{l}\text { Sensitivity } \\
(\%)\end{array}$ & $\begin{array}{l}\text { Specificity } \\
(\%)\end{array}$ & PPV (\%) & NPV (\%) \\
\hline $\begin{array}{l}\text { IVCCI } \\
(\%)\end{array}$ & 0,804 & $<0,0001$ & 46,1 & 75,4 & 79,7 & 72,9 & 81,8 \\
\hline $\begin{array}{l}\text { CSCI } \\
(\%)\end{array}$ & 0,886 & $<0,0001$ & 39,2 & 75,4 & 88,6 & 82,7 & 83,3 \\
\hline $\begin{array}{l}\text { IVCDmax } \\
(\mathrm{mm})\end{array}$ & 0,819 & $<0,0001$ & 19,6 & 63,2 & 87,3 & 78,3 & 76,7 \\
\hline $\begin{array}{l}\text { CSDmax } \\
(\mathrm{mm})\end{array}$ & 0,681 & $<0,0001$ & 11 & 64,9 & 77,3 & 67,3 & 75,3 \\
\hline $\begin{array}{l}\text { IVCDmin } \\
(\mathrm{mm})\end{array}$ & 0,839 & $<0,0001$ & 10 & 73,7 & 82,3 & 75 & 81,2 \\
\hline $\begin{array}{l}\text { CSDmin } \\
(\mathrm{mm})\end{array}$ & 0,843 & $<0,0001$ & 6,1 & 84,2 & 77,2 & 72,7 & 87,1 \\
\hline \multicolumn{2}{|c|}{$\begin{array}{l}\text { IVCDmax } / \text { BS }) \neq 67 \\
\left(\mathbf{m m} / \mathbf{m}^{\mathbf{2}}\right)\end{array}$} & $<0,0001$ & 10,6 & 64,9 & 81 & 71,2 & 76,2 \\
\hline \multicolumn{2}{|c|}{$\begin{array}{l}\text { CSDmax/BSA }, 681 \\
(\mathbf{m m} / \\
\left.\mathbf{m}^{\mathbf{2}}\right)\end{array}$} & $<0,0001$ & 5,8 & 77,1 & 58,2 & 57,1 & 78 \\
\hline \multicolumn{2}{|c|}{$\begin{array}{l}\text { IVCDmin } / \text { BSA } 818 \\
\left(\mathbf{m m} / \mathbf{m}^{\mathbf{2}}\right)\end{array}$} & $<0,0001$ & 5,8 & 68,4 & 87,3 & 79,6 & 79,3 \\
\hline \multicolumn{2}{|c|}{$\begin{array}{l}\text { CSDmin/BSA0,819 } \\
\left(\mathbf{m m} / \mathbf{m}^{\mathbf{2}}\right)\end{array}$} & $<0,0001$ & 3,6 & 78,9 & 79,7 & 73,8 & 84 \\
\hline
\end{tabular}

AUC donates area under the curve, BSA:body surface area, CS:coronary sinus, CSD:coronary sinus diameter, CSCI:CS collapsibility index, IVC:inferior vena cava, IVCCI:inferior vena cava collapsibility index, IVCD:inferior vena cava diameter, NPV:negative predictive value, PPV:positive predictive value, RAP:right atrial pressure.

Figure-1: Echocardiographic view of the Coronary Sinus and measurement of diameters with M-mode

Footnote: CS donates coronary sinüs, LV left ventricle, RV right ventricle 


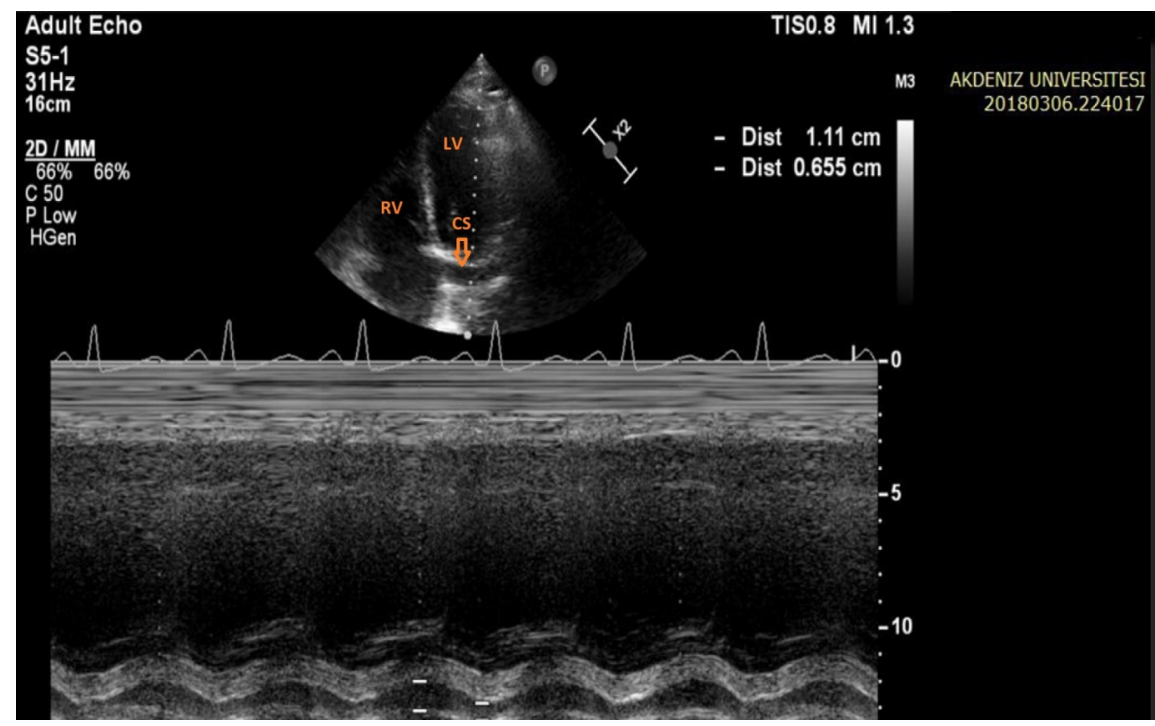

Figure-2: Comparison of IVC and CS parameters

Footnote: BSA donates body surface area, CSCI: coronary sinus collapsibility index, CSD: coronary sinus diameter, IVCCI: inferior vena cava collapsibility index, IVCD: inferior vena cava diameter

\section{Hosted file}

image2.emf available at https://authorea.com/users/435988/articles/538638-usingcoronary-sinus-diameter-and-collapse-index-to-estimate-right-atrial-pressure-forechocardiographic-systolic-pulmonary-arterial-pressure-measurement

Figure-3: Comparison of coronary sinus parameters and right artial pressure

Footnote: BSA donates body surface area, CSCI: coronary sinus collapsibility index, CSD: coronary sinus diameter, RAP: right atrial pressure

\section{Hosted file}

image3.emf available at https://authorea.com/users/435988/articles/538638-usingcoronary-sinus-diameter-and-collapse-index-to-estimate-right-atrial-pressure-forechocardiographic-systolic-pulmonary-arterial-pressure-measurement

Figure-4: Comparison of inferior vena cava parameters and right atrial pressure

Footnote: BSA donates body surface area, IVCCI: inferior vena cava collapsibility index, IVCD: inferior vena cava diameter, RAP: right atrial pressure

\section{Hosted file}

image4.emf available at https://authorea.com/users/435988/articles/538638-usingcoronary-sinus-diameter-and-collapse-index-to-estimate-right-atrial-pressure-forechocardiographic-systolic-pulmonary-arterial-pressure-measurement 